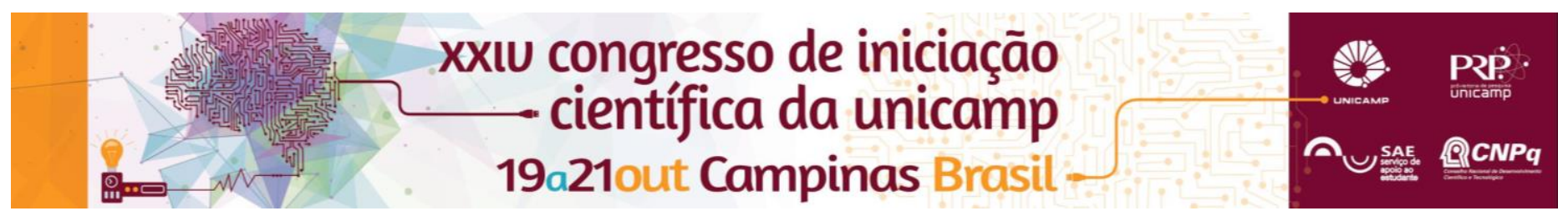

\title{
Ensino básico de programação para crianças e jovens com Scratch.
}

\author{
Igor Y. Matsuzaki, Marcos A. F. Borges.
}

\begin{abstract}
Resumo
Este projeto apresenta uma proposta de um conjunto de seis aulas, compostas por dinâmicas, teorias e práticas, fazendo uso da ferramenta de programação Scratch. As aulas foram elaboradas a partir de uma temática infantil, o conto da Chapeuzinho Vermelho, e o trabalho da arte gráfica é original do projeto. O conjunto de aulas de programação, estipulado para crianças de 10 a 13 anos de idade, pode ser aplicado em um contexto formal de ensino, em escolas que tenham carga horária específica para ensino de conteúdo computacional ou em atividades fora do contexto formal da escola, em ambientes diferentes de aprendizado, como oficinas de programação.
\end{abstract}

\section{Palavras-chave:}

Scratch, pensamento computacional, computação criativa.

\section{Introdução}

Para Fallows e Parbarry': "Ciência da Computação está tão relacionada aos computadores quanto a Astronomia aos telescópios, Biologia aos microscópios, ou Química aos tubos de ensaio. A Ciência não estuda ferramentas. Ela estuda como nós as utilizamos, e o que descobrimos com elas".

As novas tecnologias permitem que o processo de aprendizagem se crie por meio da experimentação, estimulando as descobertas e a criatividade. Para isto, é proposto o ensino de conceitos e técnicas de programação para crianças e jovens do ensino fundamental, com 0 objetivo de estimular 0 desenvolvimento de capacidades do pensamento computacional e exercitar a criatividade, o que colabora com a criação de novas soluções para o cotidiano.

Para Resnick2, no mundo em constantes mudanças, as pessoas continuamente trazem soluções criativas para problemas inesperados. O sucesso não se limita ao que as pessoas sabem ou quanto elas sabem, mas sim na habilidade de pensar e agir de forma criativa. Desenvolver tecnologia está intimamente ligado ao pensamento criativo exercitado junto ao pensamento computacional.

CSTA (Computer Science Teachers Association) e ISTE (The International Society for Technology in Education) definem que a abordagem para resolução de problemas de forma que a solução possa ser implementada utilizando um computador é chamada de pensamento computacional ${ }^{3}$.

Este projeto criou um conjunto de aulas de programação compostas por dinâmica, teoria e exercícios práticos, usando como ferramenta de programação o Scratch.

\section{Resultados e Discussão}

Este projeto inspira-se na referência do $\mathrm{Code}^{4}$, a hora do código, para se aproximar a estrutura das atividades e trabalho gráfico mais atrativo para as atividades com o Scratch. Para tal, buscou-se uma temática conhecida das crianças que iriam desenvolver as atividades deste projeto. O tema proposto foi o conto da Chapeuzinho Vermelho. Inspirada nesta decisão, a oficina de programação Scratch criada foi chamada de "Era Uma Vez".

As atividades propostas têm como objetivo fazer com que a personagem da Chapeuzinho Vermelho encontre a personagem da sua Vovó em diversos labirintos, evitando encontrar com o personagem vilão, o Lobo Mau. A Figura 1 apresenta um exemplo de labirinto.

Cada labirinto tem como objetivo explorar a capacidade dos alunos de raciocinar sistematicamente para resolver o problema do labirinto em forma de algoritmo. Para aumentar o desafio e a motivação, a cada atividade avançada o labirinto torna-se mais complexo.

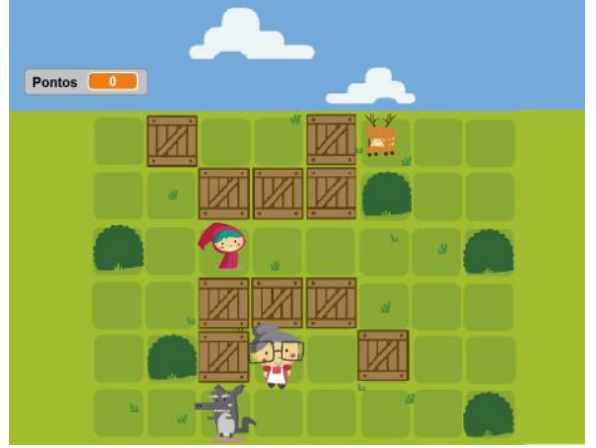

Figura 1. Labirinto Chapeuzinho Vermelho.

\section{Conclusões}

Os conceitos e práticas computacionais abordados buscam estimular e exercitar a capacidade de resoluções de problemas, pensamento sistemático e a criatividade. Este trabalho elaborou um roteiro, que descreve para o professor que venha a usá-lo todos os elementos de cada aula, além de um instrumento de avaliação para as atividades.

\section{Agradecimentos}

Agradecimento ao CNPq pelo apoio financeiro e concessão de bolsa para este projeto e auxílio, colaboração e técnica de desenho do aluno de graduação em Comunicação Social habilitação em Publicidade e Propaganda da Universidade de Sorocaba (UNISO): Bruno Porciúncula.

${ }^{1}$ Fellows, M.R., e Parberry, I., "SIGACT trying to get children excited about CS", 1993, Computing Research News.

2 RESNICK, M. Sowing the Seeds for a more Criative Society, International Society for Technology in Education (ISTE), 2007.

${ }^{3}$ CSTA - (2011) Operational Definition of Computacional Thinking

4 Code (s.d.). Anybody Can Learn. Acesso em 15 de Setembro de 2015, disponível em http://code.org/ 